\title{
مفاهيم علمية خاطئة في الإعلام العربي: "الجينات الوراثية" مثالاً
}

Misconception of scientific terms in Arabic media: genes as an example

خالد مصطفى Khaled Moustafa Editor of Arabic Science Archive (arabixiv.org) محرر الأرشيف العربي العلمي: البريد الإلكتروني: Email: Khaled.moustafa@arabixiv.org

تلعب وسائل الإعلام دوراً كبيراً في نشر وتكريس كثير من المفاهيم الصحيحة أو الخاطئة، من خلال استخدامها

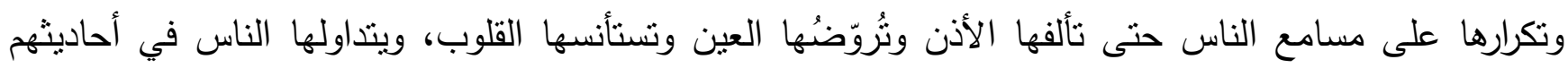
وكتاباتهم. أما إذا كانت المفاهيم صحيحة، فلا ضير في ذلك، وتلك نقطة إيجابية تُحسب لها، ولكن غالباً ما لا تسير الأمور بهذا الثكل. فكثيراً ما تشوه وسائل الإعلام، عمداً أو سهواً، كثير من المفاهيم العلمية والحياتية، وتساهم في إصدار أحكام مسبقة ومنسرعة من خلال نقل أو ترجمة خبر ما، سعياً لتحقيق سبق صحفي أو مأو "مفاجئة

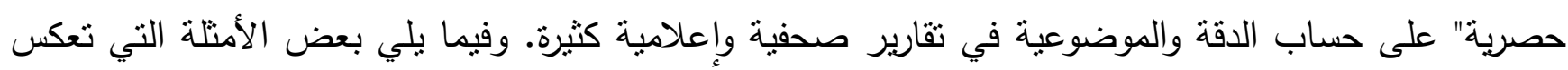
عدم تحري الدقة والموضوعية قبل اعتمادها إعلامياً في وسائل الإعلام العربية.

1) "الجينات الوراثية" (كما تسميها بعض الكتب ووسائل الإعلام العربية)

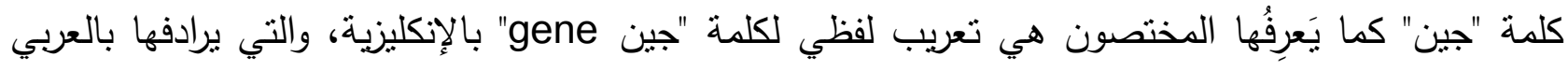

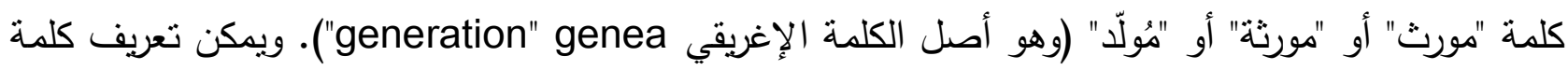
"جين" أو "مورث" بأنه "جزء من الحمض الوراثي مسؤول عن تتشفير جزيء وظيفي آخر كالحمض التعبيري mRNA

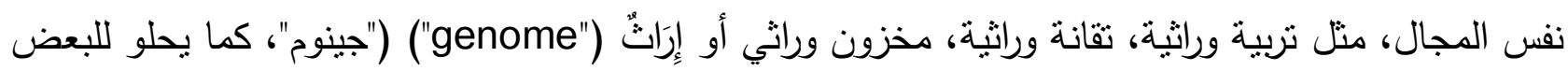

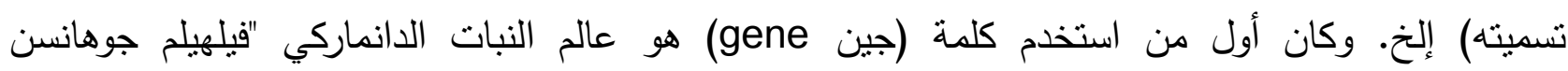
"Wilhelm Johanssen

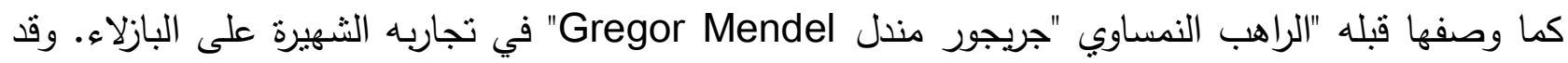
يتغير تعريف المورث مستقبلاً تبعاً للنطورات والتغيرات العلمية المنسارعة.

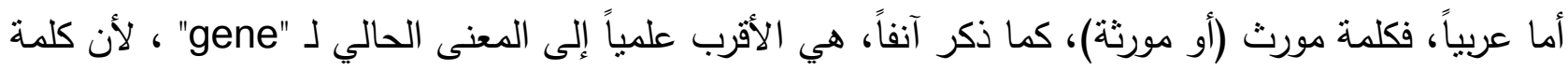

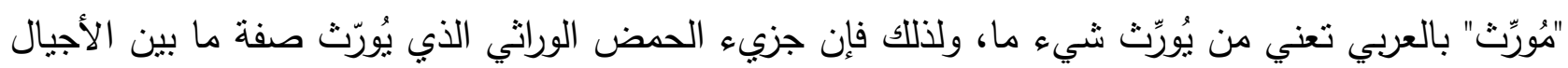

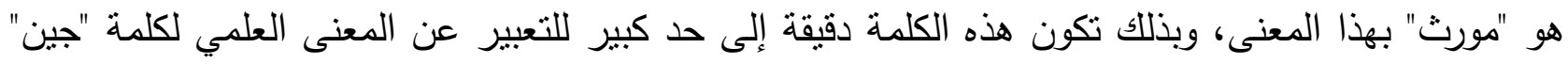
gene بالإنكليزية. وهي (أي كلمة مورث) معتمدة بهذا المفهوم في كثير من الكتب والاستخدامات العلمية 
العربية. أما كلمة "جين" فهي أيضاً مستخدمة في بعض الكتب ووسائل الإعلام العربية للالالة على نفس المعنى، وبالتالي فإن دمج كلمة (جين gene) الإنكليزية مع كلمة "مورث" أو "وراثي" العربية (وهما يحملان نفس المعنى) لتركيب جملة مثل (جينات وراثية) هو مزج لغوي غير ضروري ولا معنى لله، فهو كمن يقول

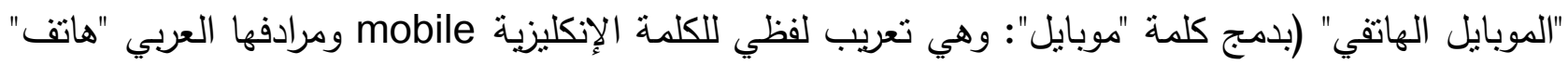
أو جوّال") أو كقول "الكمبيوتر الحاسوبي" (بمزج كلمة إنكليزية مع مرادفها العربي مرة أخرى) أو كقول: "الملح الملحي" أو "الصخر الصخري" أو كمن يقول بالإنكليزية "genetic genes"، وهذه بالطبع تعابير غير واردة وغير منطقية ولا صحيحة.

بمعنى آخر ، إن استخدام تعبير "جينات وراثية" في وسائل الإعلام العربية ليس دقيقاً علمياً، ولا يوجد مبرر لغوي أو علمي لكتابة كلمة أجنبية بأحرف عربية منبوعة بمرادفها العربي، خاصة إندات عندما يكون هذا المرادف واضح المعنى والدلالة، كما هو الحال بالنسبة لكلمة مورث هنا. وفيما يلي بعض الأمثلة التي تبين تلك المغالطة، كما تظهر في وسائل إعلام عربية حول هذا المزج اللغوي

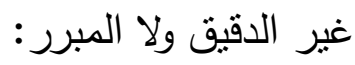
إحدى وسائل الإعلام العربية مثناً تعنون بالخط العريض: "جينات وراثية قد تسبب السرطان":

\section{جينات وراثية قد تسبب السرطان}

وهذا العنوان يُقراً من قبل أصحاب الاختصاص كالآتي: "مورثات وراثية قد تسبب السرطان"! وهذا غير دقيق لأن

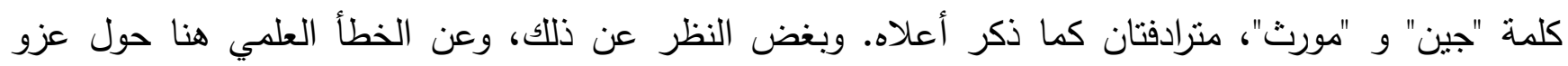
الأمراض إلى المورثات مباشرة (سواء في المحافل العربية أو الأجنبية، الذي يطول شرح تداعياته هنا)، فإن عنوان دوناً

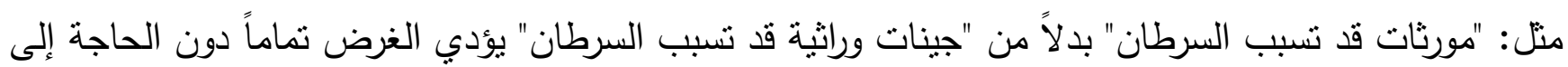
خلطة لغوية عسيرة الهضم، من نوع "جينات وراثية". وسيلة إعلامية عربية أخرى تجعل "الجينات الوراثية" عنواناً لرغبة تخصصية لإحدى النساء، فتعنون بالخط العريض: "قصة فلانة تخصصت بالجينات الوراثية..":

\section{قمة سعودية تخمست بالجينات الوراثيت..}

ومركز عربي علمي آخر ، يُقترض به أن يكون أكثر دقة وأقل غموضاً من وسائل الإعلام الصحفية يتحدث عن

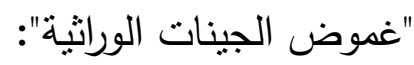




\section{اكتشافات العلماء لغموض الجينات الور اثية}

وبنفس الخطأ الدلالي والسياقي، يصف موقع آخر "الجينات الوراثية" بأنها تتحكم في "تعاطف الثخص تجاه الآخرين" ويكتب: "الجينات الوراثية تتحكم في تعاطف الثخص تجاه الآخرين":

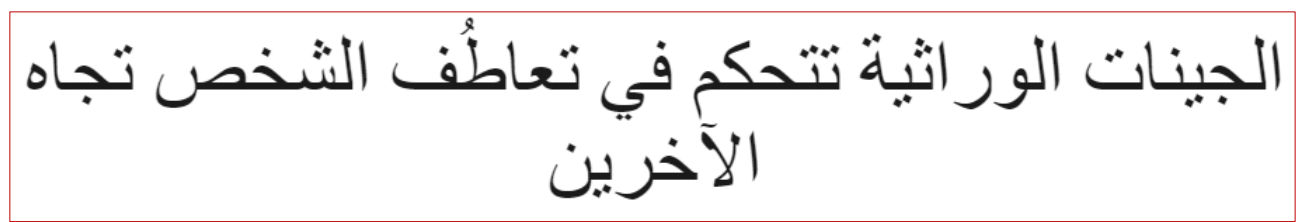

وهكذا، يعطي الصحفي هنا انطباعاً بأن وجود أو غياب التعاطف الإنساني هو أمر خارج عن الإرادة الإنسانية، وخاضع "للجينات الورثية" التي لا حيلة للإنسان التحكم بها، وهو أمر غير دقيق بطيق بطيبعة الحال.

2) المبالغة والتهويل والتعميم في بعض وسائل الإعلام العربية

تداولت بعض وسائل الإعلام العربية منذ سنوات خبراً عن وجود "مخلوقات بثماني أرجل على وجوه كل البشر":

\section{بالقةيديو.. مخلوقات بثماني أرجل على وجوه كل البشر}

وقد تكرر هذا العنوان بنفس الصيغة، أو بتعديل طفيف، في كثير من وسائل الإعلام العربية، مشيراً بهذه الصيغة

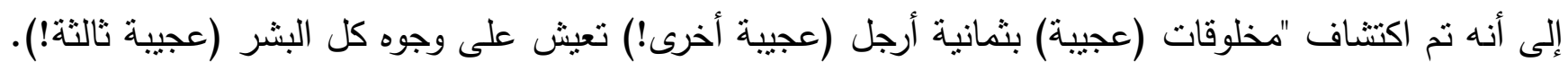
ولكن، بعد هذا العنوان التعميمي المثير للفضول والاندهاش وغير الدقيق، يضع الكاتب عنواناً آخر "رفيقة الإنسان

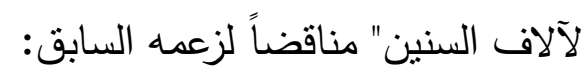

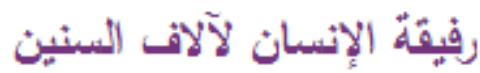

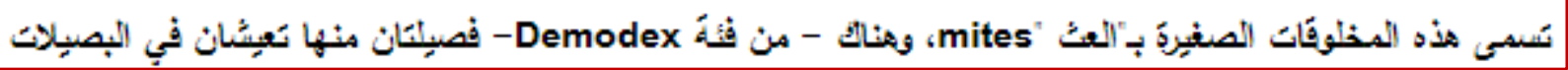

حيث يشير الكاتب إلى أن تلك المخلوقات هي العُثُ (وتسمى أيضاً السوسة أو الأرضة باللغة العربية) وهي معروفة ومألوفة منذ آلاف السنين، كما يقر الكاتب نفسه، ولكن عنوانه هنا يعطي انطباعاً كما لو أنه تم اكتشافها للتو ،

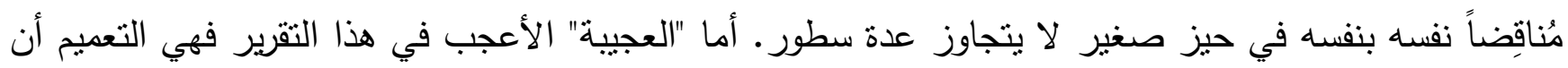
تللك المخلوقات توجد "على وجوه كل البشر" كما يؤكد الكاتب بدءاً من العنوان إلى متن التقرير ، عندما يقول مثنلاً: "توجد مخلوقات صغيرة تملك ثماني أرجل في وجوه ورؤوس 100 \% من البشر البالغين..."): 


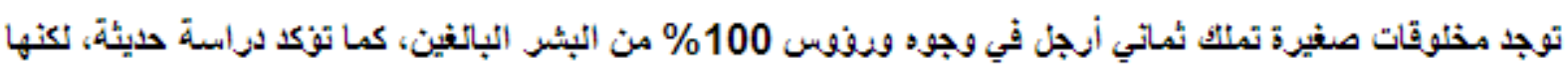

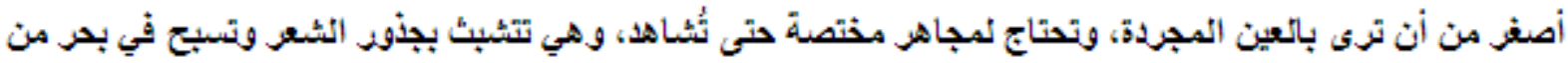

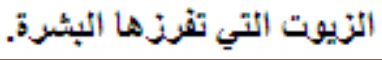

ثم يعود الكاتب ويؤكد مرة أخرى على وجود نلك المخلوقات في جميع البشر ممن تتجاوز أعمارهم "الثامنة عشرة":

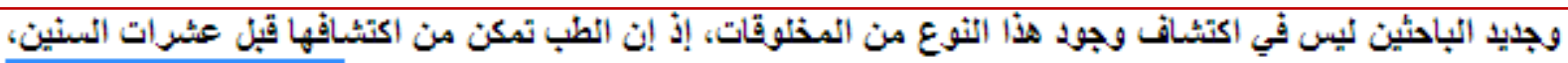

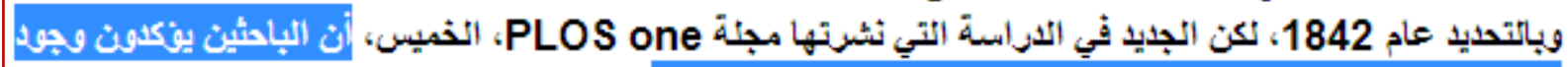

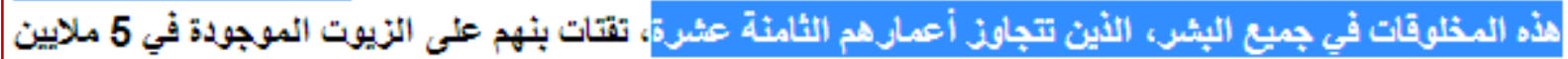

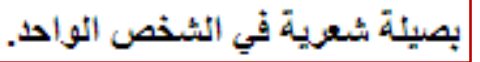

وبالعودة إلى مصدر المعلومة باللغة الإنكليزية الذي تم نقل الخبر عنه في بعض وسائل الإعلام العربية، التي ربما اقتبسته عن وسائل إعلام أجنبية قامت بدورها بتهويله والمبالغة فيه لجذب القراء لا أكثر، وهو مقالة إنكليزية بعنوان: "Ubiquity and Diversity of Human-Associated Demodex Mites" وتعني بالعربي "تنوع وعموم وجود العث المرتبط بالإنسان" وهي منشورة في المجلة المعروفة اختصاراً ب "PlosOne" على الرابط التالي:

\section{http://journals.plos.org/plosone/article?id=10.1371/journal.pone.0106265}

حيث يقول مؤلفو هذه المقالة إنهم قاموا بإجراء دراسة لتتبع وجود حشرة العث على عينة من 19 فرداً تزبد أعمارهم عن 18 سنة وعلى عينة أخرى من 10 أفراد بأعمار 18 سنة، أي بمجموع كلي قدره 29 فرداً فقط، كما هو مُبين في الثكل 1.

\begin{tabular}{|l}
$\begin{array}{l}\text { Ubiquity and Diversity of Human-Associated Demodex Mites } \\
\text { Megan S. Thoemmes, Daniel J. Fergus, Julie Urban, Michelle Trautwein, Robert R. Dunn }\end{array}$ \\
$\begin{array}{l}\text { The } 16 \mathrm{~S} \text { rDNA PCR products were separated on } 2 \% \text { agarose gels to assess presence or } \\
\text { absence of mite DNA within a sample. Non-specific amplification of human } 16 \mathrm{~S} \text { rDNA }\end{array}$ \\
$\begin{array}{l}\text { Abstract } \\
\text { occasionally occurred but was easily discernible as an approximately } 100 \text { bp larger product } \\
\text { (see Figure 1B, lane 4). For this analysis, a set of } 19 \text { individuals over } 18 \text { years of age and a } \\
\text { second set of ten individuals } 18 \text { years of age were used. Several } 16 \mathrm{~S} \text { rDNA PCR reactions }\end{array}$ \\
\hline
\end{tabular}

شكل 1. مثال عن التعميم والتهويل في بعض وسائل الإعلام عندما تعنون أخباراً غير دقيقة لنتائج دراسات معينة في إطار وظروف معينة. ففي هذا المثال، يتحدث المؤلفون عن إجراء دراسة لتتبع وجود بصمة وراثية لحشرة العث في عينة من 19 فرداً بأعمار تزيد عن 18 فئن 18 سنة

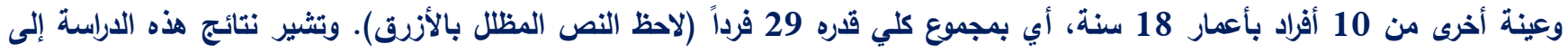
وجود البصمة الوراثية للعث في 19 فرداً، ولكن بعض وسائل الإعلام العربية أخذت النتيجة وعممتها على جميع البشر، انطلاقاً من أقل من فئن 20 فرداً فقط. 
يقول مؤلفو المقالة الإنكليزية إنهم وجدوا البصمة الوراثية للعث (وهي 18s rDNA) في جميع الأفراد البالغين المشمولين بالدراسة (أي 19 فرداً فقط). ولكن استخدامهم للنسبة المئوية (100\%) للتعبير عن ذلك هو ما قد يكون السبب الخادع والتلاعب المقصود أو غير المقصود بالألفاظ للإيحاء بأهمية النتيجة وحيثياتها، ثم أخذها بعض الته

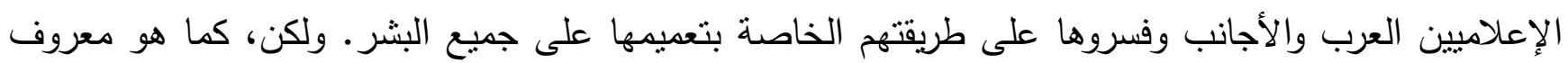

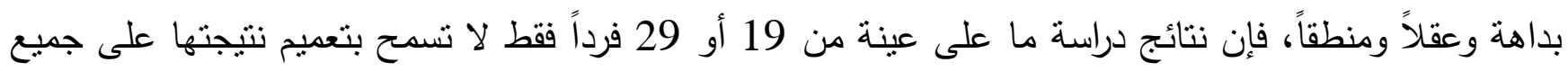

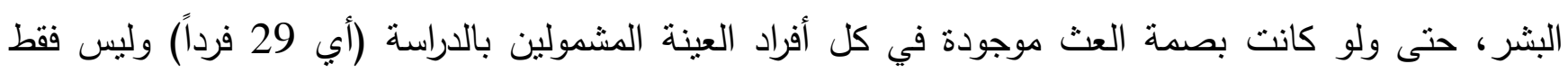

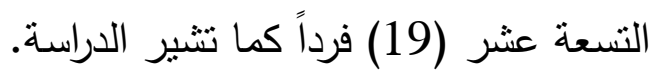

والتهويل هنا، كما يبدو ، ليس فقط من نصيب وسائل الإعلام العربية، التي نقلت أو ترجمت الخبر، وإنما أيضاً في

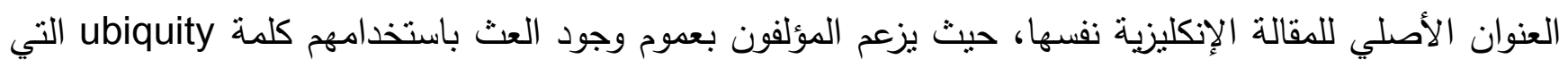
تعني وجود الثيء في كل زمان ومكان بنفس الوقت، وهو عنوان مغالط نوعاً ما، علمياً وعملياً، بالاستتاد إلى نتائج الدراسة ذاتها، التي تقتصر على عدد محدود من العينات، مما لا بسمح، مرة أخرى، بتعميم أي نتيجة مهما كانت

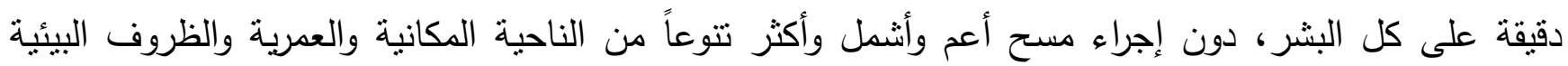
والصحية للأفراد الداخلين في الدراسة.

\section{3) عناوين المرئيات (الفيديوهات) العربية ومحتواها على الإنترنت}

كثير من أصحاب القنوات المرئية العربية على الإنترنت، وما أكثرها اليوم، يُعنونون ملفاتهم بعناوين صارخة

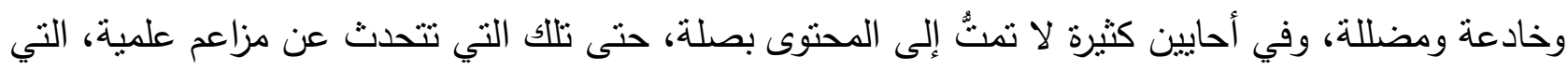

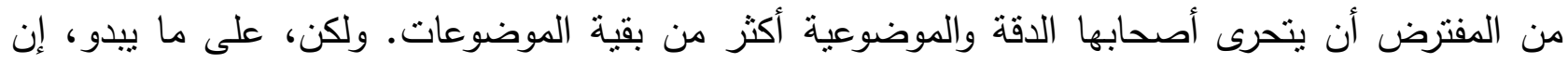
الغاية، وهي الحصول على أكبر عدد من المشاهدات، تبرر الوسيلة، وهي اختيار عناوين صارخة أو مبالغ

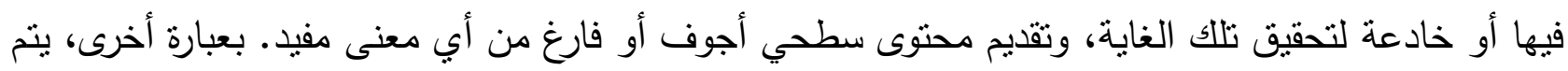
تغليب الكم والعدد (عدد المشاهدات) على حساب النوع والمصداقية والفائدة، خاصة بعد أن أن أصبحت "الفيديوهات"، بغثها الغالب وسمينها الثالب، مصدر تكسّب مادي لبعض المشاهير والمُعَلنِين. يمكن أن ينجح هذا الأسلوب المضلل مرة أو اثثتين أو بعض الوقت، ولكن هل سينجح كل الوقت؟ ذلك هو السؤال. هناك أمثلة أخرى كثيرة يطول المقام لذكرها عن المغالطة والتهويل والتضخيم والتضليل بشكل مقصود أو غير

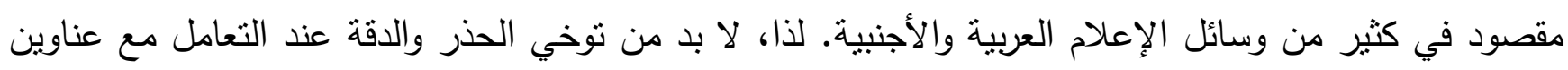

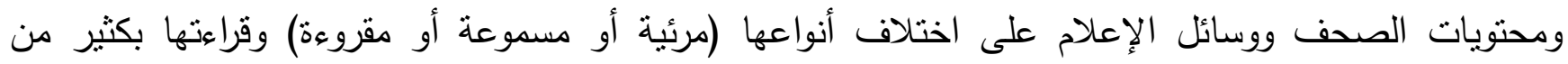


الحكمة والتروي وعدم اعتبارها مطلقة أو صحيحة إلا بعد التأكد من أصحاب العلاقة والاختصاص والثأن المُتعلّق بالمادة المقروءة.

كلمات مفتاحية: وسائل الإعلام العربية، الجينات الوراثية، التهويل الإعلامي، التضخيم الإعلامي، التضليل الإعلامي، الدقة العلمية، فيديو هات عربية، مرئيات عربية. 